\title{
Comparative Analysis of Educational Attainment among Different Social Groups in Some Selected Mouzas of Saltora C.D. Block of Bankura District, West Bengal, India: An Empirical Study
}

Krishnendu Maji ${ }^{{ }^{*}}$ and Dr Sumana Sarkar ${ }^{\top}$

\section{Abstract}

Education plays multifarious instrumental roles in the realisation of certain ends both at individual and societal level. A large number of research works carried out in and outside India have identified and established a whole range of externalities produced by education such as raising human capital beyond individual level. Despite debates on economic returns to education, most scholars agreed about the positive impact of education upon economic return. The present study has mainly focused on a comparative analysis in attainment of education among three different social groups that is, scheduled castes (SC), scheduled tribes (ST) and other non-scheduled castes at school level. This is a micro-level empirical study focusing on one of the least developed Community Development Block (CDB) of Bankura district in West Bengal. The analysis of the study reveals that disadvantaged social groups-SCs and STs are the marginalised depressed classes experiencing high level of educational deprivation compared to that of other communities. One has to note that affiliation to a particular caste can no longer be tagged as a sole determinant of relative backwardness. So what is called for is a careful stratification of the community on the basis of socio-economic attributes so as to diagnose the problem of the community at hand properly. The study uses logistic regression as an analytical tool to probe net effects of the predictor variables including castes on enrolment and discontinuation rates for the study area as a whole as well as for boys and girls separately. It is important to note that when other variables are controlled, the net effect of caste factor becomes statistically inconsequential either on enrolment or on discontinuation or dropouts. Rather, it is the combination of several socio-economic factors that are taken together which pulls down the enrolment of ST and SC children vis-a-vis those belonging to others non-scheduled castes.

Keywords: Education, Social Groups, Logistic Regression, Bankura, West Bengal, India

\footnotetext{
${ }^{\dagger}$ M.Phil, Department of Geography, The University of Burdwan, Burdwan-713104, West Bengal, India, Email: krishnendumaji58@gmail.com

* Corresponding Author

${ }^{\top}$ Assistant Professor, Department of Geography, The University of Burdwan, Burdwan 713104, West Bengal, India, Email: sumanasarkar83@gmail.com

(C)2018 Maji and Sarkar. This is an Open Access article distributed under the terms of the Creative Commons Attribution License (http://creativecommons.org/licenses/by/2.0), which permits unrestricted use, distribution, and reproduction in any medium, provided the original work is properly cited.
} 


\section{Introduction}

Education is central to development. It empowers people and strengthens nations after acting as a powerful 'equaliser', opening doors to all to lift themselves out of poverty. It is placed at the forefront of the world's attainment of the Millennium Development Goals. Education has been recognised as a powerful tool for upward social mobility, which can help to build an inclusive society by reducing socio-economic disparities(Pal Singh Chauhan, 2008: 217).The widespread of education among different segments of population helps to overcome the traditional inequalities of caste, class, and gender and so on (Ramchandran et al., 1997). Thus, 'Education is the most important single factor in achieving rapid development and increasing a social order founded on the values of freedom, social justice and equal opportunity'(Planning Commission, 1961-62). ${ }^{1}$

After nearly two decades of India's independence, the first National Policy on Education (NPE) of 1968 called for a 'radical restructuring' and equalisation of educational opportunities in order to achieve national integration and greater cultural and economic development. The next National Policy on Education (NPE) (1986) aimed not only to eliminate the social disparities entailed in the educational system but also to enhance the quality of education at Government schools. In 1994,with the implementation of the District Primary Education Programme (DPEP) along with the funding made by the World Bank, schools in India's remote rural areas were established. Subsequently, Sarva Shiksha Abhiyan (SSA) with an objective of universalisation of primary education for all was launched in 2000-2001. It focuses mainly on access to quality education, social and gender equity imparted to all children (including the physically challenged) (Planning Commission, Government of India, May 2010).

\footnotetext{
${ }^{1}$ Chapter 29: Education, 3rd Five Year Plan, retrieved on 13 March 2018 from,

http://planningcommission.gov.in/plans/planrel/fiveyr/3 rd/3planch29.html
}

In order to carry on the SSA model forward, the Government of India enacted the Right to Education Act, 2009 (RTE) as per the Article 21A of the Indian Constitution. With the enforcement of the RTE legislation on 1st April 2010, education became a child's (up to 14 years of age) fundamental right. At the same time, it puts the responsibility of enrolment, attendance and completion of education on the government.

The demographic scenario in India is such that there are vast disparities between different castes and communities in social space. Traditionally, Indian society is divided into thousands of castes, which reflect socioeconomic, educational and cultural disparities. Four of the major socio-economic categories are defined by caste combinations: Forward Castes (FCs), Scheduled Castes and Scheduled Tribes (SC/ST), and Other Backward Classes $(\mathrm{OBCs}) .^{2}$ The caste factor has the strongest

${ }^{2}$ Scheduled Castes (SCs): Certain castes, races or tribes in India, who occupy the lowest rank in the ritual hierarchy of society, were suffering from extreme social, educational and economic backwardness arising out of age-old practices of untouchability, lack of infrastructure facilities and geographical isolation, and thus, needed special consideration for safeguarding their interests and for their accelerated socio-economic development. These communities were notified as Scheduled Castes (SC) as per provisions contained in Clause 1 of Articles 341 and 342 of the Constitution and have been defined under clause 24 of Article 366 of the Constitution of India (National Commission for Schedule Castes, Government of India, retrieved on 13 March 2018 from,

http://ncsc.nic.in/pages/view/73/68-introduction Schedule Tribes (STs): Article 366(25) defined schedule tribes as "such tribes or tribal communities or parts of or groups within such tribes or tribal communities as are deemed under Article 342 to be Schedule Tribes for the purposes of this constitution"(Ministry of Tribal Affairs, Government of India, retrieved on 13 March 2018 from, http://tribal.nic.in/Content/DefinitionpRrofiles.aspx) Other Backward Classes (OBCs): The term was used early in the Mandal Commission report, issued in 1980, which included recommendations for reservation of seats for the OBCs. These were the castes between the three "higher" varnas-the Dalits (Scheduled Castes) and Adivasis (Scheduled Tribes)(National Commission for Backward Classes, Government of India, retrieved on 13 March 2018 from,

www.ncbc.nic.in/User_Panel/UserView.aspx?TypelD=11 61; 
historical roots in India. In Indian societies, right from the beginning; education was closely associated with Brahmin priests who monopolised the knowledge of Vedic tradition. While, backward communities of SCs and STs were mainly confined to occupations such as marginal farmers or labourers who did not require exposure to education to any substantial extent. On the other hand, Forward Castes (FCs) excluding OBCs constituted big land owners who not only adopted the new economic system but also took to modern education and harvested the benefits of it. Thus, the vicious circle of lower occupation and lower aspiration for education encircled the SCs and STs.

It is well argued that education by large majority is not viewed as a form of consumption; rather as an investment that involves time, energy and resources. Any investment has to be transformed into return. Viewed thus, education is a productive investment and contains functional value (Schultz, 1961). If the 'investment' does not promise any good return, hardly anyone would go in for investment in such activity. There is a close association between occupation and education and vice-versa (Sharma, 1994; Shavit and Muller, 1998). Thus, in general, the ability of the families to invest in their children's education is limited by their socioeconomic status. It, therefore, implies that education would not appeal to everyone, every social group and strata equally. Seemingly, disparity in education and academic involvement across India's different social groups or castes is yet another form of disparity and has caught up the attention of several Indian scholars(e.g. Desai, 1976; Sahoo, 1995; Balachandra, 2005; Hasan and Mehta, 2006; Dhall, 2014). After India's independence

Forward Castes (FCs): The term forward is used based on the official classification issued by the Government of India and recognised in the Constitution of India. Forward castes /communities (FCs) comprise those of the more privileged high caste individuals. The FCs have historically been and, continuous to be, in a strong socioeconomic position with the highest status in society (Sankaran et al, 2017). in 1947, a number of constitutional and legal provisions (e.g.-Article 14: Equity before Law; Article 15: Prohibition of Discrimination; Article 16: Reservation in Services; Article 17: Abolition of Untouchibility; Article 332: Reservation of Seats for Scheduled Castes and Scheduled Tribes in the Legislative Assemblies of every State)were adopted to uplift the socio-economic life of the Scheduled Castes (Ex-untouchables). But still, large gap in enrolment rate between Scheduled Castes and non-Scheduled Castes was observed. In 1981, only 35.7 per cent of Scheduled Castes children in the age group of 6-14 years were attending schools as against 53.6 percent for nonScheduled Caste children. Scheduled Caste girls were even more deprived than the boys. While 23.9 percent of Scheduled Caste girls in the age group 6-14 years were attending schools, the corresponding figure for nonScheduled Caste girls stood as high as 43.7 per cent (Aggarwal and Sibu, 1992. Thus, the attendance rate of Scheduled Caste girls was nearly half the non-Scheduled Caste girls. Bankura is one of the backward districts of West Bengal and ranks at $11^{\text {th }}$ position among the 19 districts of the state (District Human Development Report, 2007). Saltora is educationally the least developed block among all 22 blocks of Bankura district (Maji and Sarkar, 2017). While Kotulpur ranks 1st with literacy rate of 78.01 per cent, Saltora is at the bottom with just 61.45 per cent and constitutes a gender gap of 25.38 per cent. Literacy rate among the SCs and STs are 52.39 per cent and 49.21 per cent respectively, which is well below the district average (53.30 per cent and 59.18 per cent) and the state average (69.43 per cent and 57.92 per cent) of SC and ST literacy rate.

In this context, the present research work focuses on a micro-level study on some selected Mouzas of Saltora C.D. Block, Bankura District. The study aims at emphasising the role of 'caste' as well as different other socioeconomic variables on schooling in a rural context of the study area after using a holistic approach. It seeks to understand whether 'caste' alone can be said as a primary 
determining factor in terms of their literacy and educational attainment or there are other socio-economic factors, which are more influential irrespective of caste affiliation? The structure of the article has been divided into following sections. It begins with a rationale for selection of the study area including objectives of the study. This follows a brief description of the database and methodology. It then goes on to discuss the findings.

\section{Objectives of the Study}

- To assess the literacy and educational attainment across various social groups that is, Scheduled Castes, Scheduled Tribes and Other non-scheduled categories of population and disparity therein;

- To identify the dominant components of socio-cultural and economic determinants of such disparity; and

- To analyse systematically schooling and educational attainment of those social groups as socially embedded processes, influenced by broader developmental context.

\section{Location of Study Area}

Saltora Block is located in between $23^{\circ} 24^{\prime} \mathrm{N}$ and $23^{\circ} 38^{\prime} \mathrm{N}$ latitude and $86^{\circ} 50^{\prime} \mathrm{E}$ and $87^{\circ} 06^{\prime} \mathrm{E}$ longitude in the north-western part of Bankura district, West Bengal and bounded by Paschim and Purba Burdwan district in the north and Purulia district in the west (Figure 1). The present work as mentioned earlier, is confined to the eight mouzas-Saltora, Jhanka, Murulu, Bamnishala, Bamuntora, Narayanpur, Iswarda and Krishnapur (Maji and Sarkar, 2017). The Saltora Community Development Block (CDB) has been chosen for several reasons:

First, in terms of educational parameters, Saltora is positioned at the bottom among all 22 blocks in the Bankura district. Therefore, Saltora became the obvious choice (Maji and Sarkar, 2017). In terms of literacy rate, Saltora is at the bottom with literacy rate of just 61.45 per cent which is well below the district average of 70.26 per cent and state average of 77.04 per cent. As far as the gender gap is concerned, Saltora lags behind other blocks in the district with 25.38 per cent (just after Indpur, which stands at 25.62 per cent).

Second, since this study sought to examine the relative disparity across different castes, it was therefore, imperative to see that the social groups under study were fairly represented. Saltora has a comparable size of both SCs (34.19 per cent) and STs (18.9 per cent), which is above the district average of SC (32.65 per cent) and ST (10.25 per cent) population share.

Next, regarding selection of the block, steps were taken to select mouzas for primary survey. The basic consideration in selection was the social composition of population. Three kinds of mouzas were selected for the following reasons:

- First, the mouzas (Saltora, Murlu, Iswarda) where the SCs, STs and other castes are fairly in comparable proportion;

- Second, where STs are in relative majority that is, in the mouzas of Bamnishala and Krishnapur and

- Third, where SCs are in relative majority in Jhanka, Bamuntora and Narayanpur mouzas.

Apart from social composition, literacy rates of the mouzas were also taken into consideration. At the final stage, households including all social groups-SCs, STs and other non-scheduled categories were selected. Purposive random sampling technique was adopted. Table 1 illustrates the population and households covered by the survey.

\section{Database and Methodology}

Present study is mainly based on primary data. A structured questionnaire based household survey was conducted to collect information about educational, economic and demographic attributes of the population. However, qualitative and quantitative data from other 


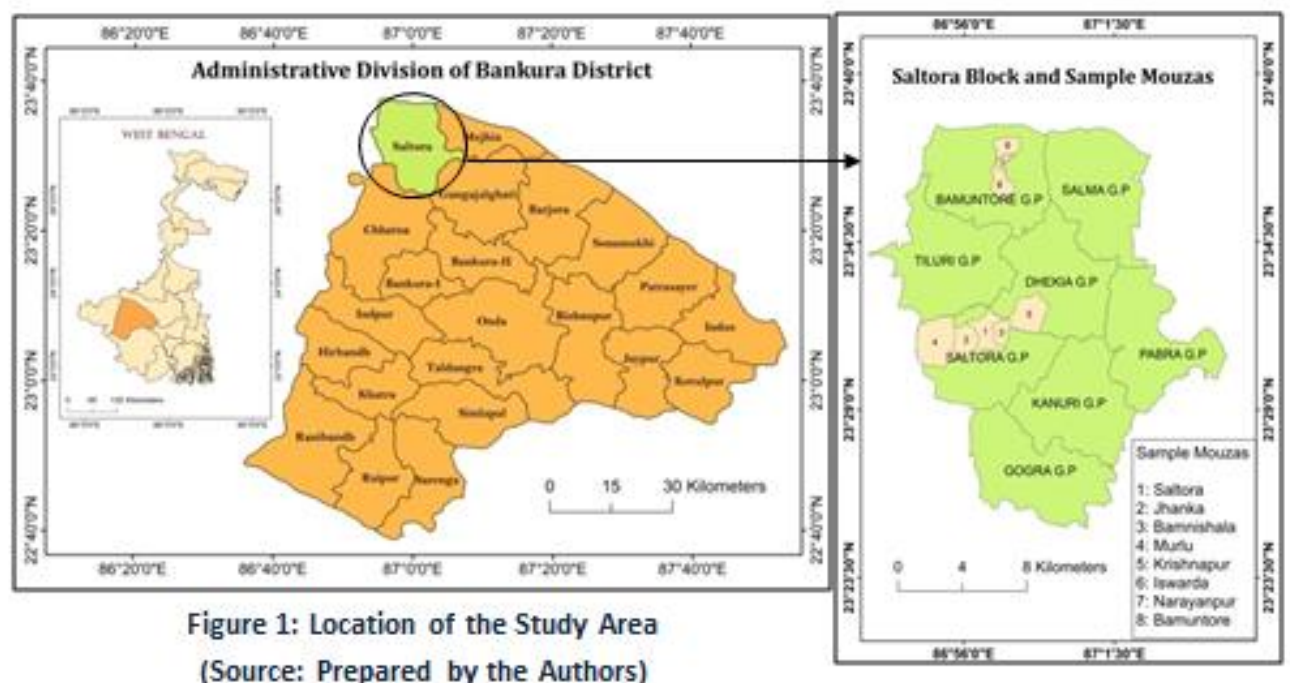

(Source: Prepared by the Authors)

Table 1: Population and Households Covered under Sample Survey

\begin{tabular}{|c|c|c|c|c|c|c|c|}
\hline \multirow{2}{*}{$\begin{array}{c}\text { Social Groups } \\
\text { Age Groups (in Years) }\end{array}$} & \multicolumn{2}{|c|}{ SC } & \multicolumn{2}{|c|}{ ST } & \multicolumn{2}{|c|}{ Others } & \multirow{2}{*}{ Total } \\
\hline & Boys & Girls & Boys & Girls & Boys & Girls & \\
\hline 7 to 15 & 42 & 42 & 28 & 36 & 52 & 61 & 261 \\
\hline 16 to 24 & 39 & 32 & 20 & 24 & 45 & 52 & 212 \\
\hline 25 to 39 & 21 & 26 & 14 & 19 & 36 & 39 & 155 \\
\hline $40+$ & 23 & 32 & 14 & 14 & 24 & 40 & 147 \\
\hline Total Population & 125 & 132 & 76 & 93 & 157 & 192 & 775 \\
\hline No. of Households & \multicolumn{2}{|c|}{66} & \multicolumn{2}{|c|}{44} & \multicolumn{2}{|c|}{78} & 188 \\
\hline$\%$ of Sample Households & \multicolumn{2}{|c|}{35.11} & \multicolumn{2}{|c|}{23.4} & \multicolumn{2}{|c|}{41.49} & 100 \\
\hline
\end{tabular}

sources including government publications are also used to conceptualise the study in wider context. Steps followed in the present study can be organised in a flow chart (Figure 2). In order to measure disparity in literacy and educational attainment across the social groups, the study employs Kundu and Rao's Index.

$$
D_{1}=\log \left(X_{2} / X_{1}\right)+\log \left[\frac{\left(200-X_{1}\right)}{\left(200-X_{2}\right)}\right]
$$

In this method, $X_{2}$ is taken for the variable having comparatively higher value and $X_{1}$ for the lower value (that is, $X_{2}>X_{1}$ ). Here, the measured value of ' $D$ ' indicates the extent of disparity. The higher the value of ' $D$ ', the higher is the extent of disparity and vice-versa.

In order to assess the net effects of selected variables, logistic regression is carried out. The logistic regression estimates the likelihood of an event to occur. The generalised logistic regression can be expressed in the following form: logit $q=\beta_{\circ}+\Sigma \beta_{i} x_{i}(i=1,2, \ldots \ldots \ldots, 6)$;

Where, $q$ is the probability of occurrence of an event;

logit $q=\ln [q /(1-q)]$ and $X_{i}(i=1,2, \ldots$. 6) are the predictor variables;

$\beta_{\mathrm{o}}$ is the intercept and $\beta_{i}^{\prime} \mathrm{s}(i=1,2, \ldots \ldots$,

$6)$ are the regression coefficients.

Here, the dichotomous variable is dependent variable and coded as 1 , if yes and 0 otherwise. The $\exp .(\beta)$ is the odds ratio representing proportional increase (if greater than 1.0) or 
decrease (if less than 1.0) for the likelihood of an event to occur.

SPSS statistical software provides a platform to generate many tables of output for analysis, of which only three main tables have been interpreted to understand the results.

- The first one is the 'Model summary' which contains the Cox \& Snell $R$ Square and Nagelkerke $R$ Square values. Both of these two are methods of calculating the explained variation. These values are sometimes referred to as pseudo $R^{2}$ values.

- Second one is the Hosmer \&Lemeshow test of the goodness of fit that suggests how good the model is to fit with the data. Model can be said good fit to the data when $p$ value (denoted by sig.)is greater than 0.05 . A chi-square statistic is computed comparing the observed frequencies with those expected under the linear model. A non significant chisquare indicates that the data fit the model well.

- The third one, the most important of all output is the Variables in the Equation table which contain the most important odds ratio or exp. ( $\beta$ ) for each variable category. It will answer questions about the association of caste, education and socio-economic status with enrolment and dropouts.

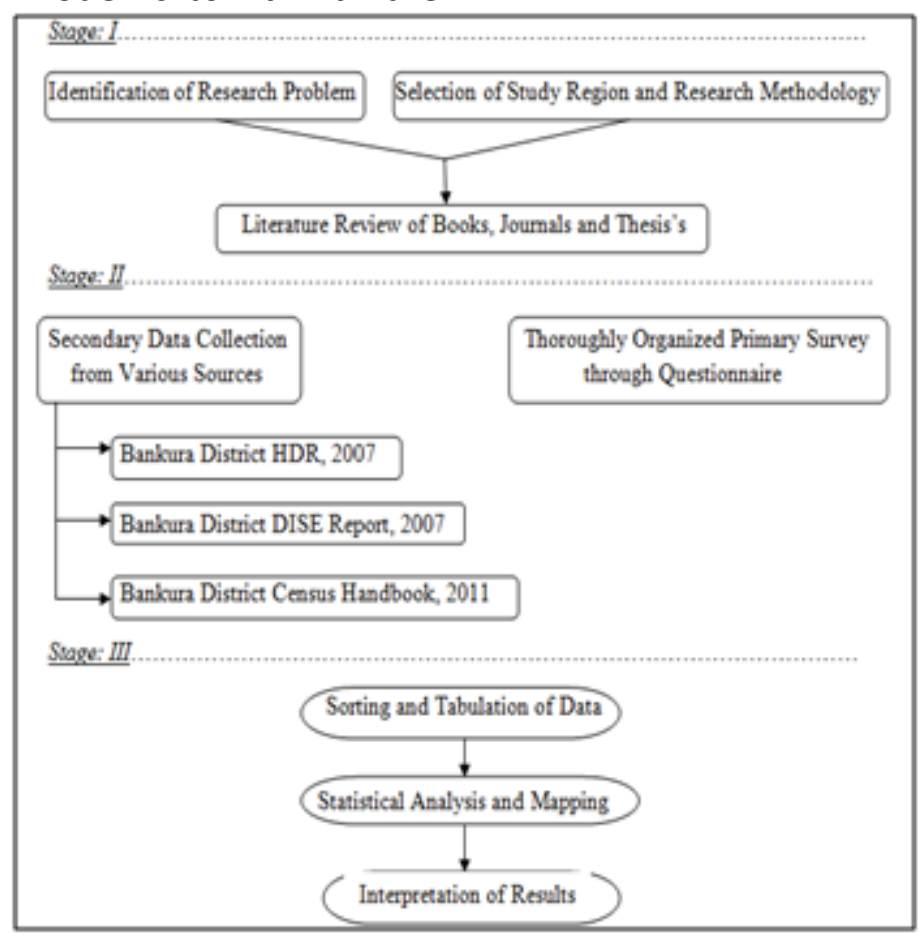

\section{Results and Discussion}

\section{Literacy Status across Social Groups}

Literacy is the basic building block and a crucial element in the development of education in society (Katiyar, 2016). The overall literacy rate of the sample population was 63.23 per cent (Table 2). Male literacy rate (70.11 per cent) was much ahead of female literacy rate, which stood at 57.31 per cent. Thus, the disparity between male and female segment stands at 0.13 (Table 3).
Literacy rate varied in terms of caste affiliation. On the whole, the STs had lower literacy levels than other two groups (Table 2). The literacy rate for other castes stood at 71.63 per cent as against 58.76 per cent for the SCs and 52.66 per cent for the STs. As far as the literacy rates of social groups by gender are concerned, among other castes, male literacy rate is $\mathbf{7 8 . 3 4}$ per cent as against 66.15 per cent literacy rates for females. Among the SCs, the male and female literacy rates are 68.8 per cent and 49.24 per cent respectively. And among STs, the gender gap is lowest, that is, 4.72 per cent. 
With this, as Table 3 shows, the gender SCs (0.19) and lowest among the STs (0.05). disparity in literacy rate is higher among the

\begin{tabular}{|c|c|c|c|c|}
\hline \multicolumn{5}{|c|}{ Table 2: Literacy Rates by Castes } \\
\hline Gender & SC & ST & Others & Overall \\
\hline Male & 68.8 & 55.26 & 78.34 & 70.11 \\
\hline Female & 49.24 & 50.54 & 66.15 & 57.31 \\
\hline Total & 58.76 & 52.66 & 71.63 & 63.23 \\
\hline \multicolumn{6}{|r}{} \\
\hline
\end{tabular}

\begin{tabular}{|c|c|c|c|}
\hline \multicolumn{5}{|c|}{ Table 3: Gender Disparity by Castes } \\
\hline SC & ST & Others & Overall \\
\hline 0.21 & 0.05 & 0.11 & 0.13 \\
\hline \multicolumn{5}{|c|}{ Source: Computed by the Authors } \\
\hline
\end{tabular}

Age-Specific Literacy Rate and Social Groups

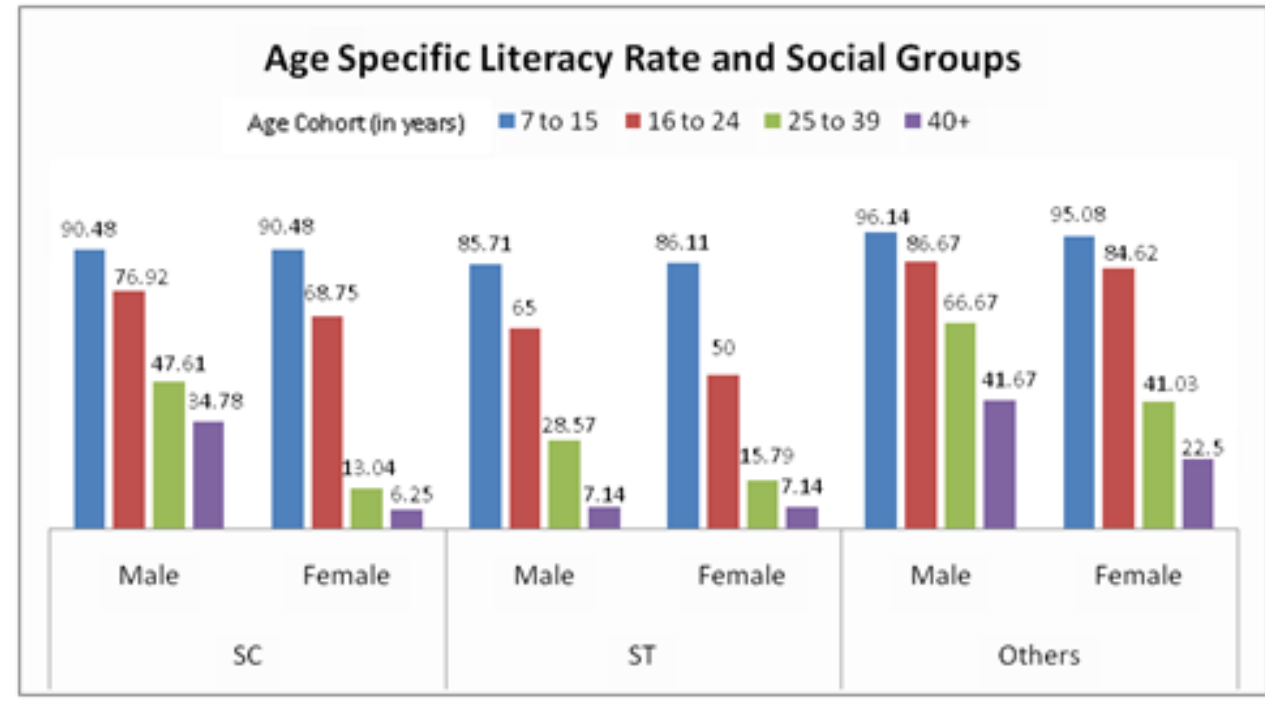

Figure 3: Age Specific Literacy Rate and Social Groups

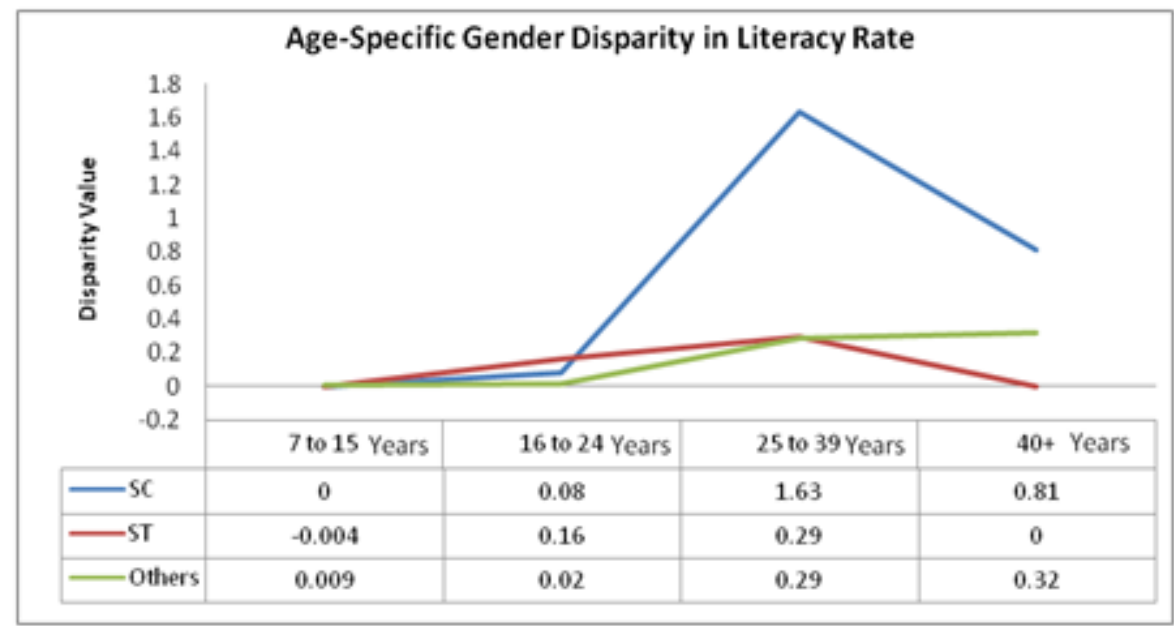

Figure 4: Age-Specific Gender Disparity in Literacy Rate

The overall literacy rate for the younger cohort corresponding figures for the age cohorts 25-39 (7 -15 years) was higher than other cohorts. years, 16-24 years and 7-15 years were 38.71 While the literacy rates for older age cohort per cent, 75.47 per cent and 91.57 percent (above 40) was 21.09 per cent, the respectively (Figure 3). Among females also, 
the younger age cohort displays impressive literacy rates than the older age cohorts. In fact, sex differential in literacy rate for the age group 7-15 years is narrow, but they become larger as we move to older age cohort.

'The younger the population cohort, the higher the literacy rate' appears to be consistently operating across the castes. Although among the SCs and STs, the literacy level is lower than among other non-scheduled castes within any age group, the disparity between the two communities tends to be remarkably low in the lower age group. For example, inter-caste disparity between SCs and other castes for the age cohort 7-15 years was 0.04 but increased to 0.11 for the age cohort $16-24$ years; to 0.35 for 25-39 years (Table 4). The faster decline in disparity of literacy rate between the two communities in younger age cohort can be explained in two ways. First, it seems that younger SC children are doing better than the earlier generation. Second, other castes had already higher literacy rates for within any age group as compared to the rests. It is observed that in a situation where literacy rate has reached the level of, say more than 75 per cent, there is little scope for rapid growth as it is closer to the point of saturation. Similar to SCs, disparity in literacy between STs and other castes was significantly high for older age cohorts (40+ age group); but that has declined over the generations as it came down to 0.08 for the younger cohort of 7-15 years age-group.

It is evident from Table 4 that while the disparity in female literacy between SC and other castes (FCs) in the older age group (above 40 years) was 0.59 , it reduced to 0.04 for the age group 7-15. Again within the community also, though gender disparity among the SCS was higher than among other castes, the gender disparity for SCs has declined as fast as among the other castes in the recent decades (Figure 4). On the other hand, for inter-caste female disparity between STs and other castes was lower than male disparity. This fact can also be explained as a result of direct involvement of large number of ST males in agricultural labour force. Therefore, it can be said that ST males are primarily more concerned of earning at the early age due to financial crisis within the families. Improvement in literacy rate from one age cohort to another, that is, from 25-39 years to $16-24$ years is much steeper in the case of SC girls (Figure 4), which is also reflected in their literacy levels (Figure 3), than boys in the corresponding age groups. ST girls have steadily improved their literacy rates over the generations. In fact, young ST girls (7-15 age cohorts) have marginally exceeded their male counterparts in terms of literacy rate.

Table 4: Age Specific Disparity in Literacy Rate with Reference to Forward Castes

\begin{tabular}{|c|c|c|c|c|}
\hline Age Group (in Years) & SC & ST & Others & Overall \\
\hline $\mathbf{7}$ to $\mathbf{1 5}$ & 0 & -0.004 & 0.009 & 0.004 \\
\hline $\mathbf{1 6}$ to $\mathbf{2 4}$ & 0.08 & 0.16 & 0.02 & 0.06 \\
\hline $\mathbf{2 5}$ to $\mathbf{3 9}$ & 1.63 & 0.29 & 0.29 & 0.38 \\
\hline $\mathbf{4 0 +}$ & 0.81 & 0 & 0.32 & 0.39 \\
\hline
\end{tabular}

Source: Computed by the Authors (based on Field Survey, 2017)

\section{Age-Specific Enrolment and Social Groups}

Age-specific enrolment rate is a significant indicator for the measurement of participation and utilisation of available educational opportunities. It reflects not only the degree of keenness of the society towards education but also the magnitude of value attached to it. Over all, about 87.42 per cent under the age between 7 and 18 years were enrolled at different levels of education. If we consider overall enrolment status of all age group, there was no significant gender bias at all (Figure 5). It is evident from Figure 5, as the age cohort increases to 18 , the enrolment rate decreases. With this, it would also be observed that gender disparity in enrolment continues to widen with the increasing age. Although at the early stage girls' enrolment marginally exceeds boys, however, in the later stage (15 to 18 
years), girls lag way behind boys. Thus, it pointed to the incidence of high dropout of girls. For about every ten children enrolled in primary-middle level, two of them dropped out before reaching ninth grade (Figure 5 ). Within the caste, gender disparities among the ST were lowest; in fact, girls were ahead of boys and as the level of education progresses, the gap between girls and boys increases in favour of girls. It seems ST boys are more prone to discontinue or not to enrol in school, mostly because they are often engage in marginal works to assist their parents financially at a very early age. For the SCs, in the age group 714 years, girls were marginally ahead of the boys (-0.02). However, hereafter girls lagged behind boys. As the age increases, disparity between boys and girls becomes acute (0.15). Among other castes, gender disparity was low (0.01) in both age groups (Figure 6).

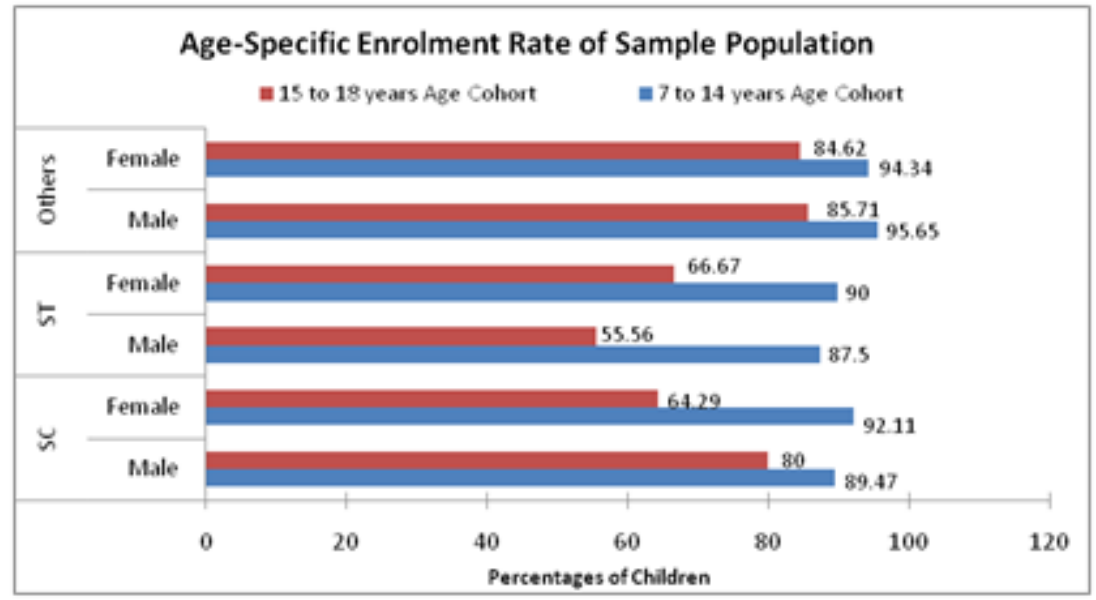

Figure 5: Age-Specific Enrolment Rate of Sample Population

\section{Educational Levels and Social Groups}

Level of education provides information about the population which is not just literate but also about the completion of an exact grade of schools. In the context of Indian society, which is essentially patriarchal, it is the women and girls who suffer because of low accessibility to education (Katiyar, 2016).

In other words, gender becomes an important factor in determining the education level of an individual (Human Development Report of India, 2011).

Of all the sample population, about 36.39 per cent had schooling up to primary-middle. The corresponding figures for the male and female were 38.83 per cent and 34.29 per cent respectively. Thus, at this level gender differential was small. A little more than onefifth of the population had reached up to secondary education and the male and female segments constituted 23.74 per cent and 18.71 per cent respectively. Thus, the study reveals that as the levels of education increase, the gender gap appears to be widening (Table 5).
It appears that girls are more prone to dropout than boys after primary-middle. But the Table 5 shows that as we move beyond the secondary level, the proportion becomes narrow, and gender disparity decreases. Only about 5.81 per cent of all the sample population were educated beyond the secondary level and females in these categories were far less represented. This can be judged by the fact that while at elementary levels the malefemale disparity was 0.07, they were comparatively high, that is, about 0.12 and 0.25 up to secondary and above secondary level respectively (Table 5). Among other castes, 40.12 per cent had attained primary-middle education. In terms of the male-female break up, the corresponding figure for other castes at primary-middle level was 41.4 per cent and 39.06 per cent respectively. It thus shows marginal gender gap (Figure 8). At this level gender disparity among the STs was a little higher (0.05) than the other caste population and the gender disparity was highest (0.14) among SC population. For SC population, the gender disparity has steadily increased as we 
move towards higher level of education. But interestingly ST females have overtaken their male counterparts in terms of attaining higher education (Figure 7). Although the actual figures are marginal, that is, only 3.23 per cent ST females have reached beyond the secondary level. This figure is well below the other two groups, but it still appears that ST females are not neglected like rest of the two groups in taking up education beyond secondary level (Figure 8).

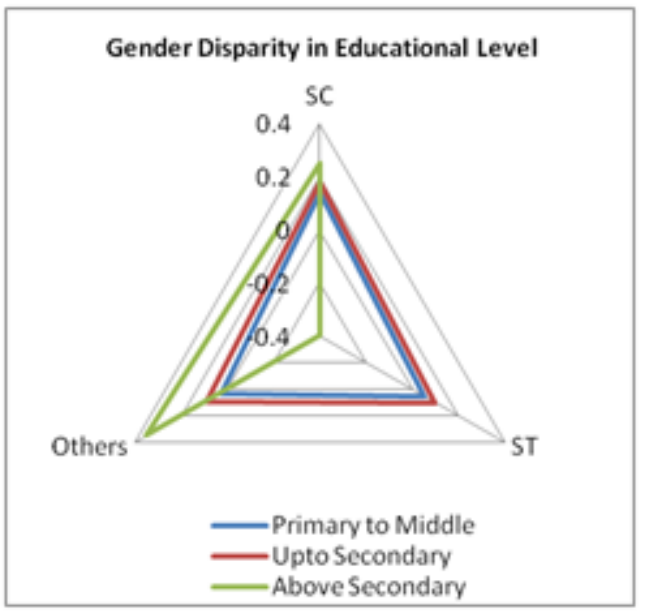

Figure 6: Gender Disparity in Enrolments Figure 7: Gender Disparity in Educational Level

\begin{tabular}{|c|c|c|c|c|}
\hline \multicolumn{7}{|c|}{ Table 5: Education Level of Sample Population: Overall at a Glance } \\
\hline Level of Education & Total & Boys & Girls & Gender Disparity \\
\hline Primary to Middle & $\mathbf{3 6 . 3 9}$ & 38.83 & 34.29 & $\mathbf{0 . 0 7}$ \\
\hline Upto Secondary & $\mathbf{2 1 . 0 3}$ & 23.74 & 18.71 & $\mathbf{0 . 1 2}$ \\
\hline Above Secondary & $\mathbf{5 . 8 1}$ & 7.54 & 4.32 & $\mathbf{0 . 2 5}$ \\
\hline
\end{tabular}

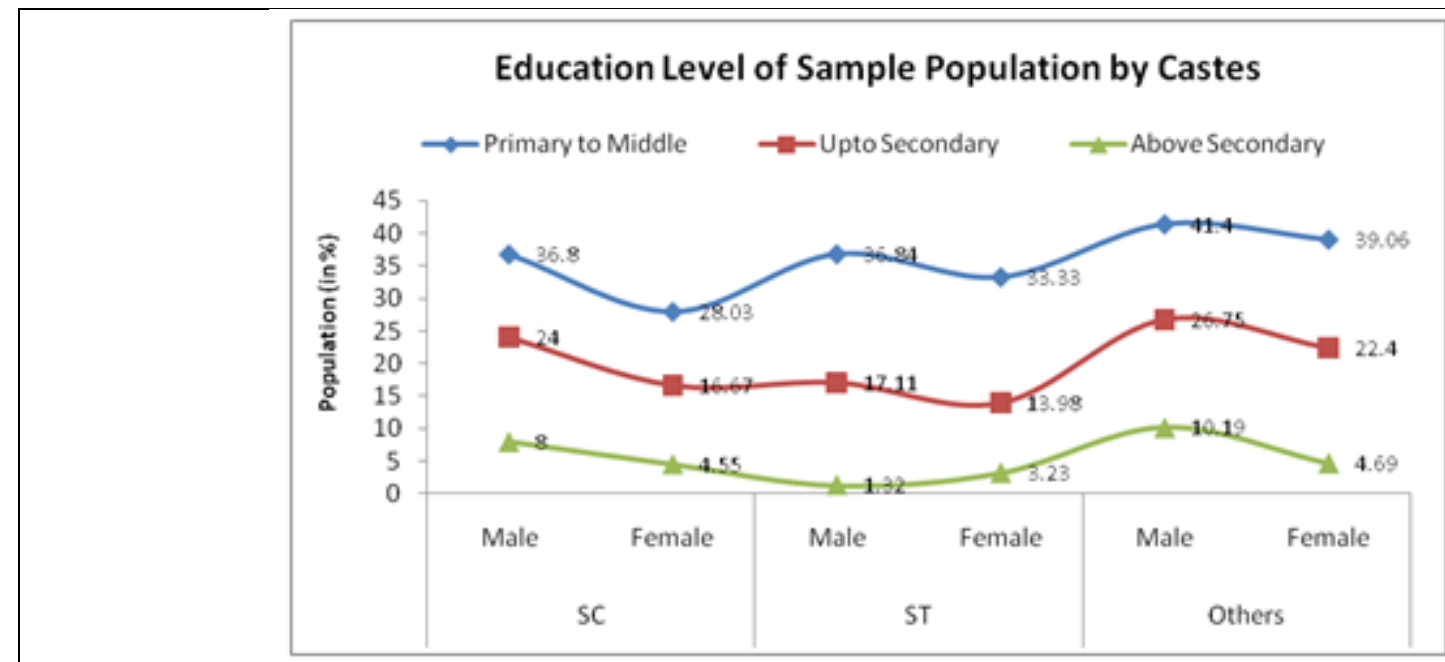

Figure 8: Education Level of Sample Population

\section{Discontinuation Rate}

The incidence of discontinuation/dropout reflects the proportion of students that drop out at various levels of education after they have been enrolled. About 22.46 per cent of children aged 7-18 had discontinued study at one or another stage of schooling (Table 6). The proportion of discontinued children was higher among the girls than the boys. As against 19.4 per cent of boys, the proportion of 
dropouts/discontinuation among the girls was 25.17 per cent. Caste wise, the discontinuation rate was highest (31.15 per cent) among the STs as against 23.33 per cent for the SCs and 17.91 per cent for other castes. Further, the discontinuation rate for the ST girls of the three groups was highest although male-female gap was very low in terms of rate of dropouts. The gender gap in discontinuation was highest (7.7 per cent) among the SCs, but for other castes, it stood at 6.31 per cent. Overall speaking, females are in general more prone to dropouts than boys.

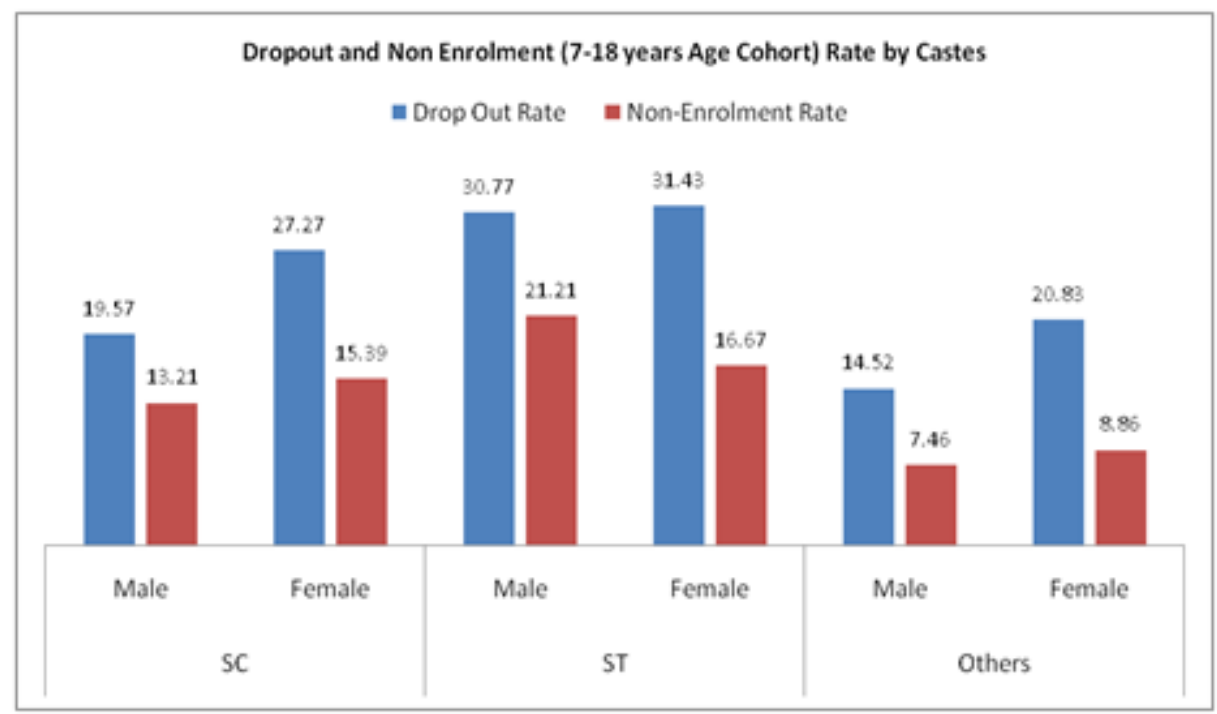

Figure 9: Drop Out and Non-Enrolment Rate of 7-18 years Age Cohort

\begin{tabular}{|l|c|c|c|c|}
\hline \multicolumn{5}{|c|}{ Table 6: Dropout and Non-Enrolment Rate of 7-18 Years Age Cohort } \\
\hline & SC & ST & Others & Overall \\
\hline Dropout Rate & 23.33 & 31.15 & 17.91 & 22.46 \\
\hline Non-Enrolment Rate & 14.29 & 18.67 & 8.22 & 12.58 \\
\hline \multicolumn{4}{|c|}{ Source: Prepared based on Field Survey, 2017 } \\
\hline
\end{tabular}

\section{Reasons for Discontinuation}

Reasons for discontinuation are quite complex. For the convenience of study, the reasons reported are broadly categorised into twoinstitutional factors and households factors (Shariff, 1995). Institutional factors accounted for about 28.13 per cent of total dropouts. However, it could be noted that institutional factors accounted a little bit more for boys than the girls. A closer look at Table 7 reveals that among the institutional factors, distance to middle school accounted for about 7.81 per cent. Further, it appears that the distance to middle school is far more responsible for girls (10.53 per cent) than the boys (3.85 per cent). Obviously, where educational institutions particularly upper-primary and secondary schools are not available or are located far away from the village, parents opted for not to go ahead with girls' education. This fact has been highlighted in other context also (Drèze and Gazdar,1996). Domestic factors are nevertheless the most important factors accounting for dropouts. Domestic factors mainly include financial constraints, marriages, domestic work, health issues, and so on. In general, poverty continues to be the major factor to be a hindrance against the continuation of children's education. These findings bear resonance to previous studies (Ghosh and Mistri, 2016; Maji and Sarkar, 2017; Sarkar and Mistri, 2017; Kaul, 2001). Of all the domestic factors, financial constraints alone accounted for 39.06 per cent. For the poor households headed by agricultural and nonagricultural labourers, the opportunity cost of children's time and direct cost of school attendance are very high. As soon as children 
approach the age of 12 to 15 years, they start contributing to the household incomes (Dinesh, 1988; Kanbargi and Kulkarni, 1991; Leiten, 2000). This argument is further reinforced by the fact that financial constraint impacted boys a little more than the girls. It points towards demand of boys in economically productive work at an early age. Table 7 reveals that financial constraints accounts are slightly more (42.11 per cent) for ST children than their counterparts in the other two communities; as opposed to38.1 per cent for SCs and 37.5 per cent for other castes. It can be explained by higher proportion of agricultural labourers (47.46 per cent) among STs than among the SCS (31.1 per cent) and other castes (11.54 per cent). This issue of financial constraints further intensified as the pressure to earn at early age increases. As much as 14.06 per cent of drop outs are due to the pressure of domestic work. Boys (19.23 per cent) are impacted more by the burden of domestic work than the girls (10.53 per cent). So, the poor economy of households (financial constraints and domestic work) alone is responsible more than half of the total dropouts. Agricultural and non-agricultural labourer households do not only have greater chances to absorb family members in the household enterprises but also have lower aspiration for education. Among other domestic factors, marriage and health issues particularly for the girls appear as most important reasons for discontinuation regardless of caste affiliation. It can be observed from Table 7, that about 23.68 per cent of girls had discontinued their study due to marriage and 5.26 per cent due to the health related issues. Although financial constraints and domestic work accounts for 36.84 per cent and 10.53 per cent of total dropout of girls, it has been observed that while boys are engaging themselves in earning wage after getting dropped out from school, girls are generally seen to be getting married.

Table 7: Reasons of Discontinuation by Castes and Sex (7 to 18 Years Age Group)

\begin{tabular}{|c|c|c|c|c|c|c|c|c|c|c|c|c|c|}
\hline \multicolumn{2}{|c|}{ Reasons of Discontinuation } & \multicolumn{3}{|c|}{ SC } & \multicolumn{3}{|c|}{ ST } & \multicolumn{3}{|c|}{ Others } & \multicolumn{3}{|c|}{ Overall } \\
\hline \multirow{4}{*}{ 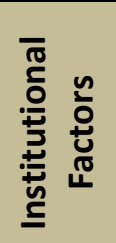 } & School too far & 4.76 & N.A & 8.33 & 5.26 & N.A & 9.09 & 12.5 & 11.11 & 13.33 & 7.81 & 3.85 & 10.53 \\
\hline & Not Interested & 23.81 & 33.33 & 16.67 & 10.53 & 25 & N.A & 20.83 & 22.22 & 6.67 & 15.63 & 26.92 & 7.9 \\
\hline & Failure & 4.76 & N.A & 8.33 & 5.26 & N.A & 9.09 & 4.17 & 11.11 & N.A & 4.69 & 3.85 & 5.26 \\
\hline & Total & 33.33 & 33.33 & 33.33 & 21.05 & 25 & 18.18 & 29.17 & 44.44 & 20 & 28.13 & 34.62 & 23.68 \\
\hline \multirow{6}{*}{ 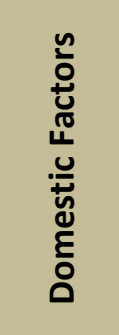 } & Financial Constraints & 38.1 & 44.44 & 33.33 & 42.11 & 37.5 & 45.46 & 37.5 & 44.44 & 33.33 & 39.06 & 42.31 & 36.84 \\
\hline & Marriage & 9.52 & N.A & 16.67 & 15.79 & N.A & 27.27 & 16.67 & N.A & 26.67 & 14.06 & N.A & 23.68 \\
\hline & Domestic Work & 14.29 & 22.22 & 8.33 & 15.79 & 25 & 9.09 & 12.5 & 11.11 & 13.33 & 14.06 & 19.23 & 10.53 \\
\hline & Got Job & N.A & N.A & N.A & 5.26 & 12.5 & N.A & N.A & N.A & N.A & 1.56 & 3.85 & N.A \\
\hline & Health Issues & 4.76 & N.A & 8.33 & N.A & N.A & N.A & 4.17 & N.A & 6.67 & 3.13 & N.A & 5.26 \\
\hline & Total & 66.67 & 66.67 & 66.67 & 78.95 & 75 & 81.82 & 70.83 & 55.56 & 80 & 71.88 & 65.39 & 76.32 \\
\hline
\end{tabular}

\section{Non Enrolment}

Since independence, although there has been impressive quantitative expansion of the system of education in India, the achievement of the goal of universalisation of primary education has still remained elusive (Sarkar and
Mistri, 2017; Maji and Sarkar, 2017; Ghosh and Mistri, 2016; Barooah, 2014; Govinda and Verghese, 1992). Table 8 presents figures on proportion of never enrolled persons in the sample population. About 36.77 per cent of total sample population was outside the school 
system. Worse was, however, the plight of female population. As against 29.89 per cent of males, about 42.69 per cent of females had never gone to school. In terms of social groups, it appears that the STs are more deprived than those of other two groups. As opposed to 28.37 per cent of other caste population being never enrolled, the corresponding figure for the SCS was 41.25 per cent and for the STs, it was as high as 47.34 per cent (Table 8). SC females appear to be the most deprived section among all. While one third of other caste females were never enrolled, the corresponding proportion for the ST females was 49.46 per cent and for $\mathrm{SCs}$, it is 50.76 per cent. Although the proportion of never enrolled males among the STs was higher than that of other two groups, yet the gender difference was not as disproportionately high as between the other two communities. Schooling of female population, especially among the older age group did not receive any attention of the household. This is evident from Figure 3, as about 86 per cent of females above 40 years of age were reported to be illiterate.

So far the enrolment of 7 to 18 years age group is concerned, overall 12.58 per cent children was out of school system (Table 6). This mostly consists ST (18.67 per cent), followed by SC (14.29 per cent) and non-scheduled (8.22 per cent) children. Gender differential was although higher among the SCs and other castes than the STs, it can be seen that among the STs, more males compared to the females had failed to get enrolled (Figure 9).

\begin{tabular}{|c|c|c|c|}
\hline \multicolumn{3}{|c|}{ Table 8: Non-Enrolled Person (All Age Groups) in Percentage } \\
\hline Castes & Total & Male & Female \\
\hline SC & 41.25 & 31.2 & 40.76 \\
\hline ST & 47.34 & 44.74 & 33.85 \\
\hline Others & 28.37 & 21.66 & $\mathbf{4 2 . 6 9}$ \\
\hline Overall & $\mathbf{3 6 . 7 7}$ & $\mathbf{2 9 . 8 9}$ & \\
\hline \multicolumn{2}{|c|}{ Source: Prepared based on Field Survey, 2017 } \\
\hline
\end{tabular}

Household Characteristics of Non-enrolled poverty is by far the most important reason for Persons

It is apparent from the research that that education of the head appears to be one of the major determining factors as to whether a child would ever been in school (Table 9). About 26.19 per cent out of the total of 36.77 per cent never enrolled persons belonged to the illiterate heads. As the educational level of the head of the household increases, the propensity of non enrolment declines sharply regardless of caste affiliations and sex of children. In brief, the educated parents have the first-hand experience of the benefits of education and therefore, would like to see same benefits being appropriated by their children. In terms of occupation, it is the agricultural labourers whose children are most likely to be never enrolled (Table 9). It seems schooling of females are more neglected by the household headed by agricultural labourers. The findings thus exemplify the findings of other researches showing that non enrolment (Dasgupta and Tilak, 1983; Bhatty, 1998; Banerjee, 2000; Jabbi and Rajyalakshami, 2001). As compared to agricultural labourers, the children of cultivators (except for a few marginal farmers) and those engaged in self-employment other than cultivation are relatively less likely to be not enrolled in schools. It is because in these occupations, though the chance of absorption of children is quite high, parents may not only desire but can also support the children for some time to get some levels of education; but in the case of agricultural labourers not only is there lack of motivation and low aspiration for education but also have a poor financial support for getting their children into school. In short, poor people (agricultural labourers and marginal farmers) are short of resources including many of the resources that are deployed in education (Conell, 1994). This is further confirmed when we look at the incidence of non-enrolment by standard of living. It is clear from the Table 9, that the 
children of those belonging to family of low standard of living have higher(27.23 per cent) propensity of not being ever enrolled than those of high standard of living. Discontinuation of children from schooling has several implications for educational attainments. It is because even though children are enrolled; some of them do not continue. This gets more crucial as certain segments of population and within the given segment; girls become more prone to dropouts than boys of the same age groups. The main problems faced by the females of the scheduled population are absence of female teachers of their own community, in-conducive socio-economic environment, early marriage, prejudices against their mobility, excessive involvement in the household chores, inadequate transport facilities and toilet facilities, etc. thereby, accentuating the gender disparity in literacy rate among the scheduled population (Karlekar, 1983; Sarkar and Mistri, 2017).In the study area, discontinuation rates for STs were slightly higher than that of other two castes (Figure 9). Although gender discrimination seems to be more among the SCs as the gap between drop-out rates of two genders is more widening.

\begin{tabular}{|c|c|c|c|c|c|c|c|c|c|c|c|c|c|}
\hline \multicolumn{14}{|c|}{ Table 9: Percentage of Non Enrolled Persons by Household Characteristics } \\
\hline \multirow{2}{*}{\multicolumn{2}{|c|}{ Household Characteristics }} & \multicolumn{3}{|c|}{ SC } & \multicolumn{3}{|c|}{ ST } & \multicolumn{3}{|c|}{ Others } & \multicolumn{3}{|c|}{ Overall } \\
\hline & & $\begin{array}{l}\bar{\pi} \\
\stackrel{0}{\circ} \\
\vdash\end{array}$ & $\frac{\tilde{y}}{\sum}$ & $\begin{array}{l}\frac{\tilde{U}}{\tilde{\sigma}} \\
\stackrel{\tilde{\Xi}}{\Psi} \\
\dot{L}\end{array}$ & $\begin{array}{l}\bar{\pi} \\
\stackrel{0}{\circ}\end{array}$ & $\frac{\tilde{v}}{\sum \pi}$ & 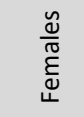 & $\begin{array}{l}\overline{\widetilde{0}} \\
\stackrel{0}{\circ}\end{array}$ & $\frac{\frac{\mathscr{U}}{\pi}}{\sum}$ & $\begin{array}{l}\frac{\mathscr{U}}{\widetilde{\varpi}} \\
\frac{\tilde{\Xi}}{\sqcup} \\
\sqcup\end{array}$ & $\begin{array}{l}\bar{\pi} \\
\stackrel{0}{0}\end{array}$ & 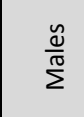 & 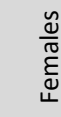 \\
\hline \multirow{4}{*}{$\begin{array}{c}\text { Education } \\
\text { of Head of } \\
\text { the } \\
\text { Household }\end{array}$} & Illiterate & 24.9 & 20.8 & 28.79 & 36.1 & 35.53 & 36.56 & 22.35 & 16.56 & 27.08 & 26.19 & 22.07 & 29.74 \\
\hline & Primary-Middle & 14.79 & 9.6 & 19.7 & 11.24 & 9.21 & 12.9 & 5.44 & 5.1 & 5.73 & 9.81 & 7.54 & 11.75 \\
\hline & Secondary or above & 1.56 & 0.8 & 2.27 & N.A & N.A & N.A & 0.57 & N.A & 1.04 & 0.77 & 0.28 & 1.2 \\
\hline & All & 41.25 & 31.2 & 50.76 & 47.34 & 44.74 & 49.46 & 28.37 & 21.66 & 33.85 & 36.77 & 29.89 & 42.69 \\
\hline \multirow{6}{*}{$\begin{array}{c}\text { Occupation } \\
\text { of Head of } \\
\text { the } \\
\text { Household }\end{array}$} & Cultivator/Farmer & 13.62 & 9.6 & 17.42 & 15.39 & 13.16 & 17.2 & 6.88 & 5.1 & 8.33 & 10.97 & 8.38 & 13.19 \\
\hline & Agricultural Labour & 22.57 & 16 & 28.79 & 29.59 & 28.95 & 30.11 & 21.49 & 16.56 & 25.52 & 23.61 & 18.99 & 27.28 \\
\hline & Non-Agricultural Labour & 3.89 & 4.8 & 3.03 & 2.37 & 2.63 & 2.15 & 0.86 & N.A & 1.56 & 2.19 & 1.96 & 2.4 \\
\hline & Self Employed & 1.17 & 0.8 & 1.52 & N.A & N.A & N.A & N.A & N.A & N.A & 0.39 & 0.28 & 0.48 \\
\hline & Services & N.A & N.A & N.A & N.A & N.A & N.A & N.A & N.A & N.A & N.A & N.A & N.A \\
\hline & All & 41.25 & 31.2 & 50.76 & 47.34 & 44.74 & 49.46 & 28.37 & 21.66 & 33.85 & 36.77 & 29.89 & 42.69 \\
\hline \multirow{4}{*}{$\begin{array}{l}\text { Standard of } \\
\text { Living }\end{array}$} & Low & 27.63 & 20 & 34.85 & 35.5 & 34.21 & 36.56 & 22.92 & 18.47 & 26.56 & 27.23 & 22.35 & 31.42 \\
\hline & Medium & 13.23 & 11.2 & 15.15 & 11.83 & 10.53 & 12.9 & 5.44 & 3.19 & 7.29 & 9.42 & 7.54 & 11.03 \\
\hline & High & 0.39 & N.A & 0.76 & N.A & N.A & N.A & N.A & N.A & N.A & 0.13 & N.A & 0.24 \\
\hline & All & 41.25 & 31.2 & 50.76 & 47.34 & 44.74 & 49.46 & 28.37 & 21.66 & 33.85 & 36.77 & 29.89 & 42.69 \\
\hline \multicolumn{14}{|c|}{ Note: N.A denotes 'Not Applicable' (where $N$ is 0 ) } \\
\hline
\end{tabular}

\section{Determinants of Gender-Specific Enrolment}

The $R^{2}$ (Table 10) values tell us that for the overall enrolment, approximately 25 per cent to 47 per cent variation in the outcome is explained by the explanatory variables. Moving onto the Hosmer \&Lemeshow test (Table 11) of the goodness of fit, it suggests the model is a good fit to the data as all the $p$ values are greater than 0.05 .

So far the gender specific enrolment is concerned, when other variables are controlled for, education of the head of the households, particularly those educated beyond middle or secondary level seems to have significant and positive impact on the continuity of education of their children. Better living status appears to have significant influence on the probability of getting children enrolled as compared to households with low standard of living. But this association is not as straight forward as it could be observed that same net effect is not observed in case of girls (Table 12).In this context, it is important to note that in bi- 
variate analysis, standard of living did show a positive bearing on girls' chances to be enrolled.

The 'deviation' when regression analyses is applied may be because of stronger 'pull factors' (sometimes even non-quantifiable parameters) operating such as 'distance of schools' and 'marriage', as discussed above, which mitigates the effect of living standard of the households. It may be recalled from the earlier discussion that educational attainment of children varies in terms of occupation of the head of the household as there is a closer link between occupation and aspiration for education. Children of those heads who belongs to the households of agricultural and non-agricultural labourers are less likely to be enrolled than other occupational categories.

The higher the age cohort, chances of enrolment becomes lower. While absence of employment opportunity (26.92 per cent of total dropout of boys) might account for boys more than for girls, the negative association between schooling and age in case of girls can largely be attributed to marriage as universal construct. Marriage (23.68 per cent of total dropout of girls) as a reason for dropout or discontinuation does emerge as one of the major factors in the study area. Along with these, financial constraints accounts for 42.31 per cent and 36.84 per cent of total dropout for boys and girls respectively.

\begin{tabular}{|c|c|c|c|c|c|}
\hline \multicolumn{2}{|c|}{ Table 10: Model Summary on Logistic Regression of Gender-Specific Enrolment } \\
\hline $\begin{array}{c}\text { Overall } \\
\begin{array}{c}\text { Cox \& Snell } R \\
\text { Square }\end{array}\end{array}$ & $\begin{array}{c}\text { Nagelkerke } R \\
\text { Square }\end{array}$ & $\begin{array}{c}\text { Cox \& Snell } R \\
\text { Square }\end{array}$ & $\begin{array}{c}\text { Nagelkerke } R \\
\text { Square }\end{array}$ & $\begin{array}{c}\text { Cox \& Snell } R \\
\text { Square }\end{array}$ & $\begin{array}{c}\text { Nagelkerke } R \\
\text { Square }\end{array}$ \\
\hline 0.252 & 0.474 & 0.295 & 0.548 & 0.238 & 0.454 \\
\hline \multicolumn{4}{|c|}{ Source: Calculated by the Authors } \\
\hline
\end{tabular}

Table 11: Hosmer and Lemeshow Test on Logistic Regression of Gender-Specific Enrolment

\begin{tabular}{|c|c|c|c|c|c|c|c|c|}
\hline \multicolumn{3}{|c|}{ Overall } & \multicolumn{3}{c|}{ Boys } & \multicolumn{3}{c|}{ Girls } \\
\hline Chi-square & $d f$ & Sig. & Chi-square & $d f$ & Sig. & Chi-square & $d f$ & Sig. \\
\hline 3.651 & 8 & 0.887 & 1.089 & 8 & 0.998 & 1.312 & 8 & 0.995 \\
\hline \multicolumn{8}{|c|}{ Source: Calculated by the Authors } \\
\hline
\end{tabular}

\section{Determinants of Dropouts or Discontinuation}

As per the $R^{2}$ values(Table 13), the explained variation in the dependent variable (that is, dropouts) based on the model ranges approximately 24 to 38 per cent for males and for the dropout of females, the model explains around 13 to 19 per cent of the variation in outcome. There seem to be a wide range of factors that are present uniformly irrespective of social status or caste affiliation. That is the reason why the model for dropout of females is not able to explain the variation satisfactorily. Although Hosmer \&Lemeshow test (Table 14) of the goodness of fit suggests that the model is a good fit to the data as all the $p$ values are greater than 0.05 .It could be observed from the Table 15, that in a multivariate regression when other variables are controlled, caste does not appear to be as significant as education and standard of living of house head in influencing children's chances to stay at school. The overall likelihood of children continuing or completing a grade is about 5 times and 2 times higher for the children belonging to households where heads are educated up to secondary and above secondary level respectively, as compared to the children coming from households headed by illiterates. In general, the occupation of the head of the household seems to have important bearing on whether the child will continue schooling. Table 15 shows that when controlling for all other variables, the children of those engaged in services are least likely to discontinue their schooling. 


\begin{tabular}{|c|c|c|c|c|c|c|c|c|c|}
\hline \multicolumn{8}{|c|}{ Table 14: Hosmer and Lemeshow Test on Logistic Regression of Dropouts } \\
\hline \multicolumn{3}{|c|}{ Overall } & \multicolumn{3}{c|}{ Boys } & \multicolumn{3}{c|}{ Girls } \\
\hline Chi-square & $d f$ & Sig. & Chi-square & $d f$ & Sig. & Chi-square & $d f$ & Sig. \\
\hline 9.165 & 8 & 0.329 & 8.176 & 8 & 0.416 & 5.403 & 8 & 0.714 \\
\hline \multicolumn{8}{|c|}{ Source: Calculated by the Authors } \\
\hline
\end{tabular}

\begin{tabular}{|c|c|c|c|c|}
\hline \multicolumn{5}{|c|}{ Table 15: Logistic Regression on Dropout (7 to 18 Years Age Group): Sample Mouzas } \\
\hline \multirow{2}{*}{\multicolumn{2}{|c|}{ Predictor Variables }} & Overall & Males & Females \\
\hline & & $\operatorname{Exp}(\beta)$ & $\operatorname{Exp}(\beta)$ & $\operatorname{Exp}(\beta)$ \\
\hline \multirow{3}{*}{ Social Groups } & Other Castes (rc) & & & \\
\hline & SC & 0.813 & 0.636 & 0.759 \\
\hline & ST & $0.577 * *$ & $0.375^{* *}$ & 0.646 \\
\hline \multirow{3}{*}{$\begin{array}{l}\text { Education of } \\
\text { Head of the } \\
\text { Household }\end{array}$} & Illiterate (rc) & & & \\
\hline & Up to Secondary & $2.116 * *$ & $2.741 * *$ & 2.073 \\
\hline & Above Secondary & $5.571^{*}$ & $8.222^{*}$ & $4.550 * *$ \\
\hline \multirow{5}{*}{$\begin{array}{l}\text { Occupation of } \\
\text { Head of the } \\
\text { Household }\end{array}$} & $\begin{array}{l}\text { Agricultural Labours } \\
\text { (rc) }\end{array}$ & & & \\
\hline & Cultivators/Farmers & 1.454 & 1.686 & 1.565 \\
\hline & Non-Agri Labours & 0.759 & 0.541 & 1.028 \\
\hline & Self-Employed & 1.165 & 0.729 & 1.572 \\
\hline & Services \& Others & 1.094 & N.A & 1.022 \\
\hline \multirow{3}{*}{$\begin{array}{l}\text { Standard of } \\
\text { Living }\end{array}$} & Low (rc) & & & \\
\hline & Medium & $2.518^{*}$ & $3.476^{*}$ & 1.961 \\
\hline & High & 1.827 & N.A & 1.114 \\
\hline \multicolumn{2}{|c|}{ Total Observations } & 285 & 134 & 151 \\
\hline \multicolumn{5}{|c|}{ rc: Reference Category (Note: Predicted probability is of membership for continuing or completed) } \\
\hline \multicolumn{5}{|c|}{$\begin{array}{l}\text { N.A: 'Not Applicable' (either subset sample too small or subset of predictors perfectly predicts the } \\
\text { outcome) }\end{array}$} \\
\hline \multicolumn{5}{|c|}{ * The coefficient in the underlying logistic regression differs significantly from zero at the $5 \%$ level } \\
\hline \multicolumn{5}{|c|}{ ** The coefficient in the underlying logistic regression differs significantly from zero at the $10 \%$ level } \\
\hline \multicolumn{5}{|c|}{ Source: Computed by the Authors (based on Field Survey, 2017) } \\
\hline
\end{tabular}

\section{Conclusion}

The analysis of the study shows that the extent of disparities existing among the SCs and the STs of Saltora are much higher in comparison to the others communities. The present enquiry tries to establish with certain conviction that literacy and caste disparities in schooling are not independent of socio-economic context; in this case, all three social groups respond as homogeneous groups. It becomes clear that rather than positing SCs, STs and other (nonscheduled) castes for that matter as undifferentiated category, we need to see which economic strata of the community are being interrogated in terms of caste influences on various attributes. To conclude then, schooling as a social variable is a complex issue and become more complex when 'caste factor' is incorporated. And any understanding has necessarily to be apprehended in multi-layered ways placing the discussion in a wider analytical framework.

\section{References}

Aggarwal, Y.P and Sibu Sarika (1992). Educating Scheduled Castes, New Delhi: NIEPA

Balachandra M. (2005). Growth and Social Justice, Yojana, Vol. 49, pp.9-11. 
Banerjee, Rukmani (2000). Poverty and Primary Schools, Economic and Political Weekly, Vol. 35(10), pp. 799-802

Barooah, M. (2014). Spatial Pattern and Variation in Literacy among the Scheduled Castes Population in the Brahmaputra Valley, Assam. Space and Culture, India, 2(1), 24-32. https://doi.org/10.20896/saci.v2i1.68

Bhatty, Kiran (1998). Educational Deprivation in India: A Survey of Field Investigation, Economic and Political Weekly, Vol. 33(28), pp. 17311739

Chandra Pal Singh Chauhan (2008). Education and caste in India, Asia Pacific Journal of Education, Vol. 28 (3), pp. 217-234.

Connel, R.W (1994). Poverty and Education, Harvard Educational Review, Vol. 64 (2), pp. 125-49

Dasgupta, A and Tilak, J.B.G (1983). Distribution of Education among Income Groups: An Empirical Analysis, Economic and Political Weekly, Vol. 18 (33), pp. 1442-1447

Desai, I.P (1976). Untouchability in Rural Gujarat, Bombay: Popular Prakashan

Dhall, S. (2014).A Study of Academic Achievement among Adolescents in Relation to Achievement Motivation and Home Environment, Journal of All India Association for Educational Research, Vol. 26 (1), pp. 1- 6.

Dinesh, B.M (1988). Economic Activities of Children: Dimensions, Causes and Consequences, New Delhi: Daya Publishing House

\section{District Census Handbook of Bankura: Village} and Town Wise Primary Census Abstract (PCA), Series-20, Part XII-B, 2011

District Human Development Report: Bankura, Development \& Planning Department, Government of West Bengal; April, 2007.

Drèze, J and Gazdar, H (1996).Uttar Pradesh: Burden of Inertia. In Drèze, J and Sen, A.K (eds.), Indian Development: Selected Regional Perspective, New Delhi: Oxford University Press.
Education for Peace and Sustainable

Development: Concepts, Clarity and Cohesion, A Set of Papers commissioned by Mahatma Gandhi Institute of Education for Peace and Sustainable Development, retrieved 17 April 2018 from, http://unesdoc.unesco.org/images/0022/0022 75/227521e.pdf

Govinda and Verghese, V.V. (1992). Quality of Primary Education: An Empirical Study, Journal of Educational Planning and Administration, Vol.6 (1), pp.17-35.

Ghosh M. and Mistri B. (2016). Literacy Rates and its Impact on Birth Rates in Nadia District, West Bengal, India, Space and Culture, India, 5(2), pp. 80-92, https://doi.org/10.20896/saci.v5i2.268

Hasan, R. and Mehta, A. (2006).Underrepresentation of Disadvantaged Classes in Colleges: What Do the Data Tell Us?, Economic and Political Weekly, Vol. 41 (35), 379- 396.

Human Development Report of India (2011), retrieved 21 April 2018

from,http://hdr.undp.org/sites/default/files/re ports/271/hdr_2011_en_complete.pdf

Jabbi, M.K and C Rajyalakshami (2001). Access to Education of Marginalized Social Groups in Bihar. In Vidyanathan, A and P.G.R Nair (eds.), Elementary Education in Rural India- A Grass Roots View: Strategies in Human Development, New Delhi: Sage Publications

Kanbargi, Rand P.M Kulkarni (1991). Child Work, Schooling and Fertility in Rural Karnataka. In Kanbargi (ed.), Child Labour in the Indian Subcontinent: Dimensions and Implications, New Delhi: Sage Publications

Karlekar M. (1983). Education and Inequality. In Andre Beteille (ed), Equality and InequalityTheory and Practice, New Delhi: Oxford University Press

Katiyar, S. P (2016). Gender Disparity in Literacy in India, Social Change, and Vol.46 (1), pp. 4669

Kaul Rekha (2001). Accessing Primary Education Going beyond the Classroom, Economic and Political Weekly, Vol. 36 (1), pp. 155-162 
Lieten, G.K (2000). Children, Work and Education, Economic and Political Weekly, Vol.35 (2), pp. 2171-2178

Maji, K. (2017). Educational Disparities among Different Social Groups in Saltora Block of Bankura District (W.B.), India: A Micro-level Geographical Study, M.Phil Dissertation, The University of Burdwan, Burdwan.

Maji and Sarkar (2017). Intra-District Disparities in Primary Education: A Case Study of Bankura District, West Bengal, Space and Culture, India, Vol. 4(3), pp. 77-92, https://doi.org/10.20896/saci.v4i3.214

Ministry of Tribal Affairs, Government of India, retrieved 24 April 2018 from, http://tribal.nic.in/Content/DefinitionpRrofiles .aspx

National Commission for Backward Classes, Government of India, retrieved 24 April 2018 from, www.ncbc.nic.in/User_Panel/UserView.aspx?T ypelD=1161

National Commission for Schedule Castes, Government of India, retrieved 24 April 2018 from http://ncsc.nic.in/pages/view/73/68introduction

Planning Commission, Government of India, 3rd Five Year Plan, retrieved 24 April 2018 from, http://planningcommission.gov.in/plans/planr el/fiveyr/3rd/3planch29.html

Ramchandran, V.K., Rawal Vikas and Swaminathan, Madhura (1997). Investment Gaps in Primary Education: A State wise Study, Economic and Political Weekly, Vol. 32 (1-2), pp. $39-45$

Sahoo, F.M. (1995). Combating Learning Helplessness of Scheduled Castes and
Scheduled Tribes School Students, Independent Study, Rural Initiative for Self-Reliance and Education, Bhubaneswar (ERIC Funded), NCERT, New Delhi

Sarkar A. and Mistri, B. (2017). Home Environment as Strong Determinant in Academic Involvement of Female Students in Dhekia Gram Panchayat of Saltora C.D. Block, Bankura District, Space and Culture, India, 5(2), pp.97-116, https://doi.org/10.20896/saci.v5i2.268

Schultz, T.W (1961). Investment in Human Capital, American Economic Review, 51, pp. 1-1 7

Sankaran, S., Sekerdej, M., \& von Hecker, U. (2017). The Role of Indian Caste Identity and Caste Inconsistent Norms on Status Representation, Frontiers in Psychology, 8, 487, http://doi.org/10.3389/fpsyg.2017.00487

Shariff Abusaleh (1995). Socio-Economic and Demographic Differentials between Hindus and Muslims, Economic and Political Weekly, Vol.18, pp.2947-53.

Sharma, R.D. (1994). A Comparative Study of Expenses of the Educational Institutions of Secondary Education of Rural and Urban Areas of Mehsana District and Their Impact upon the Pupils Achievements, PhD Thesis, Sardar Patel University, Vallabh Vidyanagar

Shavit, Y and W. Muller (1998). The Institutional Embeddedness of the Stratification Process: A Comparative Study of Qualification and Occupation in Thirteen Countries. In Shavit, $Y$ and W. Muller (eds.), From School to work: $A$ Comparative Study of Educational Qualification and Occupational Destination, New York: Clarendon Press, pp.1-48 